\title{
Antioxidant Potential and Phenolic Contents of Various Flaxseed Cultivars from Different Agro-Industrial Regions
}

\author{
Nazia Yaqoob ${ }^{1}$, Huma Munir ${ }^{1}$, Farheen Aslam², Rehana Naseer ${ }^{1}$, Shagufta Kamal ${ }^{3}$, \\ Shabbir Hussain ${ }^{4 *}$, Maryam Rashid ${ }^{1}$, Shahida Shujaat ${ }^{5}$, Arif Nazir ${ }^{6}$, Munawar Iqbal ${ }^{6 * *}$ \\ ${ }^{1}$ Department of Chemistry, Government College Women University, Faisalabad, Pakistan \\ ${ }^{2}$ Department of Biotechnology, Lahore College for Women University, Lahore, Pakistan \\ ${ }^{3}$ Department of Applied Chemistry and Biochemistry, GC University, Faisalabad, Pakistan \\ ${ }^{4}$ Department of Chemistry, Lahore Garrison University, Lahore, Pakistan \\ ${ }^{5}$ Department of Chemistry, Lahore College for Women University, Lahore, Pakistan \\ ${ }^{6}$ Department of Chemistry, The University of Lahore, Lahore, Pakistan
}

Received: 30 September 2020

Accepted: 25 January 2021

\begin{abstract}
This study focuses on the evaluation of antioxidant activity, phenolic and flavonoids contents of selected flaxseed cultivars, native to Pakistan. Antioxidant activities were determined using 2, 2-diphenyl-1-picrylhydrazyl (DPPH) radical scavenging activity, ferric ion reducing ability and inhibition of linoleic acid peroxidation (LAP). Total phenolic content (TPC) was determined using FolinCiocalteu reagent, whereas colorimetric method was used to assess total flavonoids (TF). The TPC, TF, $\mathrm{DPPH}^{\circ}$ scavenging activity and LAP were 2560 to $3286 \mathrm{mg}$ gallic acid equivalent (GAE)/100 g, 232.53 to $346.67 \mathrm{mg}$ catechin equivalent (CE)/100g and 63.08 to $86.58 \%, 65.59$ to $84.25 \%$, respectively. Results of the present study revealed that flaxseed cultivars possess varying degree of antioxidant capacity and therefore may be considered as a potent source of natural antioxidants.
\end{abstract}

Keywords: flaxseed cultivar, antioxidant activity, phenolics, flavonoids, colorimetry

\section{Introduction}

Flax (Linum usitatissimum) is cultivated for oil and fiber since ancient time, belongs to Linum genus and Linaceae family. It is used as food ingredient and natural laxative [1] and is also a valuable source of bioactive compounds [2]. Nowadays, natural antioxidants have

*e-mail: dr.shabbirhussain@1gu.edu.pk

**e-mail: chemuaf@gmail.com attracted the attention of food technologists in food industry for the stability of food products and to protect it from degradation. Polyunsaturated fatty acids in fat and oil are degraded as a result of natural oxidation process, which leads to food spoilage and rancidity. Rancidity changes food flavor and degrades the food nutritional quality. So far, to avoid this dilemma, the antioxidants are used to preserve flavor and food degradation. Butylated hydroxytoluene (BHT), butylated hydroxyanisole (BHA), tert-butyl hydroquinone, vitamin $\mathrm{C}$ and $\mathrm{E}$ are synthetic antioxidants employed 
for food stabilization, but these have been restricted due to their carcinogenic activity [3-5]. Therefore, natural antioxidants are of great interest since these are safe and number of researchers highlighted their efficiency. Plants have an abundance of natural antioxidant compounds (secondary metabolites), which consists of variety of phytochemicals. Studies revealed that consumption of diet rich in antioxidants reduced the cardiovascular disease, neurodegenerative disease and cancer incidences [6-8]. The phenolic compounds have promising potential in health as nutritional supplements, herbal medicines and ROS-related disease as chemo preventive agents. Besides, these compounds play a significant role in preventing foods from oxidative damage. Different parts of vegetables, cereal crops, oilseeds and herbs have been reported to be potential sources of natural antioxidant. The oil seed crops are the richest source of antioxidants [9].

Flaxseed contains $40 \%$ oil and is gaining the recognition as a dietary ingredient irrespective of its traditional usage [1]. Flaxseed consumption controls tumor growth, cholesterol, and cancer (breast, prostate, and colon). The health benefits of flaxseed are correlated with presence of activities of $\alpha$-linolenic acid, lignin's, protein, phenolic acid and flavonoids [10-13]. Pakistan, being an agricultural country is blessed with medicinally important flora and crops. Flaxseed has been conventionally grown in Pakistan for the extraction of oil from the seeds. Therefore, the principle objective of this investigation was to assess the antioxidant activity and phenolic compounds in flaxseed native to Pakistan.

\section{Material and Methods}

Eight different cultivars of flaxseed were selected and compared for their antioxidant potential and phenolic compounds. The Chandni, LS-108, LS-105, LS-99 and LS-29 flaxseed cultivars were obtained from Ayub Agricultural Research Institute (AARI), Faisalabad, Pakistan, whereas LS-33, LS-31 and LS-13 were obtained from National Agricultural Research Center (NARC) Islamabad, Pakistan.

All the chemicals and reagents were purchased from Sigma Aldrich (USA) and Merck (Germany). Dried and grounded ( $80 \mathrm{~mm}$ mesh size) seeds were defatted. The defatted seed residues $(20 \mathrm{~g})$ were mixed with $200 \mathrm{~mL}$ of aqueous ethanol (Ethanol: Water, 80:20 v/v) and extracted by shaking for $8 \mathrm{~h}$ at $25^{\circ} \mathrm{C}$. After $8 \mathrm{~h}$, the contents were sonicated for $45 \mathrm{~min}$ and filtered. The residues extracted twice, extracts were combined and evaporated using rotary evaporator (EYELA, Tokyo, Japan) and subjected to analysis.

The TPC was assessed using Folin-Ciocalteu reagent based analysis [14]. TF were precisely determined as reported elsewhere. The TF contents were expressed as CE/100 g dry weight (DW). The free radical scavenging activity was estimated [15] and the antioxidant activity of flaxseed extracts was determined in terms of percentage inhibition of peroxidation in a linoleic acid system [15]. The antioxidant activity was calculated using relation shown in Eq. (1). Reducing power was determined following already reported method [16].

$$
A A=100-\frac{\beta-\alpha}{\beta *-\alpha *} \times 100
$$

...where, AA is inhibition of peroxidation, $\beta$ is absorbance of sample at $72 \mathrm{~h}, \beta^{*}$ is absorbance of control at $72 \mathrm{~h}, \alpha$ is absorbance of sample at $0 \mathrm{~h}$ and $\alpha^{*}$ is the absorbance of control at $0 \mathrm{~h}$.

Extraction/hydrolysis of phenolic compound was carried out [17]. HPLC (Waters Alliance 2695) equipped with YMC-Pack ODS AM-303, C18 column (250 mm x $4.6 \mathrm{~mm}$ x $5 \mu \mathrm{m})$, and Agilent series 1050 diode array detector, (UV $254 \mathrm{~nm}$ ) was used for analysis. The temperature of the column maintained at $30^{\circ} \mathrm{C}$. Two solvent systems i.e. $0.2 \%$ trifluoracetic acid and acetonitrile $(90: 10 \mathrm{v} / \mathrm{v})$ were used as mobile phase. The chromatographic separation was performed by isocratic elution of the mobile phase at a flow rate of

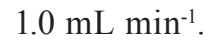

All experiments were performed in triplicates and data, thus obtained was reported as the mean \pm SD. Data were analyzed by analysis of variance (ANOVA) and the Duncan multiple range (DMR) test (Version 16.1). A $P<0.05$ was considered to denote statistically significant differences.

\section{Results and Discussion}

The TPC \& TFC of flaxseed cultivars extracts are given in Table 1. The TPC found out to be in the range of 2560 to $3286 \mathrm{mg}$ GAE/100g. However, TPC varied significantly among cultivars $(P<0.05)$. The TPC varies in extracts and different plant and species showed variables TPCs since the growing conditions as well as method and solvent used for extraction affect the concentration in extracts. The TPC are in line with reported results [18]. These authors reported the flaxseed antioxidant capacity and the solvent (polarity) effect. This antioxidant activity found to be variable among solvents, which indicates that appropriate solvent selection is important for the extraction of bioactive compounds. Methanol (80\%) gave good yield and the TPC and TFC contents also found to be variable among solvents. Ethanol (80\%) showed higher TFC along with promising antioxidant capacity. Results showed that the polar solvents enable maximum extraction of phenolic and flavonoid compounds. The phenolic content was recorded comparatively higher than reported.

The TFC were 232.53 to $346.67 \mathrm{mg} \mathrm{CE} / 100 \mathrm{~g}$ range (Table 1) and among different cultivars, the variation was significant $(P<0.05)$. The TFC observed values were in close agreement previously reported results for different Canadian flaxseed cultivars. However, 
Table 1. Total Phenolic contents, flavonoid contents, DPPH radical scavenging activity (\%), inhibition of linoleic oxidation (\%) and reducing power (absorbance) of ethanolic extracts of different cultivars of flaxseed.

\begin{tabular}{|c|c|c|c|c|c|}
\hline Cultivars & $\begin{array}{c}\text { TPC (mg GAE/100g } \\
\text { of DW) }\end{array}$ & $\begin{array}{c}\text { TFC (mg CE/100g } \\
\text { of DW) }\end{array}$ & DPPH Scavenging & $\begin{array}{c}\text { Inhibition of linoleic } \\
\text { oxidation }\end{array}$ & Reducing power \\
\hline Chandni & $3251 \pm 128^{\mathrm{ab}}$ & $321.67 \pm 8.62^{\mathrm{b}}$ & $86.58 \pm 4.00^{\mathrm{a}}$ & $84.25 \pm 3.5^{\mathrm{a}}$ & $1.628 \pm 0.052^{\mathrm{abc}}$ \\
\hline LS -108 & $3286 \pm 138^{\mathrm{a}}$ & $346.67 \pm 6.03^{\mathrm{a}}$ & $75.99 \pm 2.86^{\mathrm{ab}}$ & $82.22 \pm 2.4^{\mathrm{a}}$ & $1.646 \pm 0.044^{\mathrm{ab}}$ \\
\hline LS -105 & $3249 \pm 119^{\mathrm{ab}}$ & $342.91 \pm 10.36^{\mathrm{a}}$ & $74.59 \pm 1.90^{\mathrm{bc}}$ & $85.29 \pm 1.4^{\mathrm{a}}$ & $1.662 \pm 0.062^{\mathrm{a}}$ \\
\hline LS -99 & $3190 \pm 126^{\mathrm{ab}}$ & $319.67 \pm 14.51^{\mathrm{a}}$ & $70.02 \pm 0.99^{\mathrm{bcd}}$ & $73.5 \pm 2.9^{\mathrm{b}}$ & $1.617 \pm 0.068^{\mathrm{abcd}}$ \\
\hline LS -33 & $2958 \pm 99^{\mathrm{bc}}$ & $284.12 \pm 5.29^{\mathrm{ab}}$ & $67.00 \pm 3.66^{\mathrm{cd}}$ & $72.45 \pm 3.75^{\mathrm{b}}$ & $1.691 \pm 0.035^{\mathrm{a}}$ \\
\hline LS- 31 & $2943 \pm 81^{\mathrm{bc}}$ & $325.52 \pm 4.58^{\mathrm{a}}$ & $69.75 \pm 1.66^{\mathrm{bcd}}$ & $73.65 \pm 1.5^{\mathrm{bc}}$ & $1.462 \pm 0.056^{\mathrm{b}}$ \\
\hline LS -29 & $2740 \pm 114^{\mathrm{c}}$ & $294.05 \pm 10.82^{\mathrm{ab}}$ & $65.29 \pm 1.20^{\mathrm{cd}}$ & $68.90 \pm 2.9^{\mathrm{bc}}$ & $1.471 \pm 0.061^{\mathrm{cd}}$ \\
\hline LS -13 & $2560 \pm 71^{\mathrm{c}}$ & $232.53 \pm 10.06^{\mathrm{b}}$ & $63.06 \pm 3.56^{\mathrm{d}}$ & $65.59 \pm 2.7^{\mathrm{c}}$ & $1.501 \pm 0.59^{\mathrm{bcd}}$ \\
\hline
\end{tabular}

Values (mean \pm SD) are average of three samples of each cultivar, analyzed individually in triplicate $(\mathrm{n}=2 \times 3 \times 3),(P<0.05)$.

Different letters in superscript (columns) indicate significant differences among different flaxseed cultivars

the TFC observed in this study are significantly greater than reported from Egyptian (12.9-20.0 mg/100 g) [19]. The difference of TFC values in comparison to reported values can be explained on the basis of ability of solvent to extract bioactive compounds, different chemical composition, nature of soil and agro-climatic condition [18].

$\mathrm{DPPH}^{\circ}$ is commonly used radical for the assessment of antioxidant activity in plant extracts and natural products. Absorbance was recorded at 0.5 to $10 \mathrm{~min}$ from the initiation of the reaction. The observed radical scavenging activity (RSA) changed as reaction time increased until stabilization was reached after $10 \mathrm{~min}$. The DPPH of the flaxseed extracts found out to be in the range of 63.08 to $86.58 \%$, and variation among different cultivars was significant $(P<0.05)$. The results are in close agreement to the previous findings i.e. DPPH from Egypt was reported to be in the range of 81.6 to $89.3 \%$ [20], $78.38 \%$ of $50 \%$ aqueous ethanolic extract from Indian origin. In another study, butanol was used for extraction and in comparison to the present investigation, flaxseed grown in Indian region used less DPPH as compared to BHA and BHT [21]. This revealed that the antioxidant activity may vary from region to region even in same cultivar. Furthermore, the cultural practices and different agro-ecological and weather conditions are responsible for variation in quality.

The flaxseed extracts exhibited appreciable inhibition of per-oxidation, which was found to be in the range of 65.59 to $84.25 \%$. The variation in the inhibition capacity may be attributed to the variation in TPC and TFC. The percentage inhibition of LAP system in the present study was found consistent with the previous reports in which the inhibition of LAP in the presence of flaxseed extracts has been reported to be comparable to BHT [18].

The reducing power (RP) of extracts also reveal promising antioxidant activity in the extracts, in which the ferric ions are reduced to ferrous ions and color is changed from yellow to bluish green. The change in color reveals antioxidant potential [18], which was promising for flaxseed extracts. The RP of the extracts was found to be concentration dependent, which is an electron donating ability to neutralize the ions. Results of flaxseed RP in present investigation are comparable to the previous report of reducing potential of ethanolic extracts of flaxseed from Indian origin [21].

A good correlation $(\mathrm{r}=0.8810)$ was observed between TPC and TFC, which could be supported by the previously reported trends [22]. Moreover, a relation between TPC and DPPH $(r=0.8254)$ was observed, which is also good indication of antioxidant since TPC are the scavengers of ROS. Similarly, TFC $(r=0.6964)$ also revealed good correlation with ROS. An excellent correlation between inhibition of LAP, TPC $(r=0.9216)$, TFC $(r=0.8197)$ and DPPH assays $(\mathrm{r}=0.9051)$ was observed. The RP also correlated well with TPC and TFC ( $r=0.9484),(r=0.7519)$, respectively. The RP also showed good correlation with inhibition of LAP $(\mathrm{r}=0.9306)$ and reasonable correlation with DPPH RSA $(r=0.7026)$. These results are in accordance with the previous investigations [18, 21], who reported that extracts rich in TPC may act as powerful scavengers of ROS with good RP. Variations observed in the present investigation in correlation coefficients support the necessity to use different assays to assess antioxidant efficacy of plant extracts.

The representative HPLC chromatograms of standard and phenolic compound are shown in Fig. 1. The content of all the detected phenolic compounds (acids, flavonoids and lignin's) varied significantly among flaxseed cultivars. The most abundant compound present in the flaxseed were lignin's i.e. secoisolariciresinol diglucoside (SDG) and secoisolariciresinol (SECO), which was in the range of 14.78 to 124.27 and 396.49 to $1518.2 \mathrm{mg} / 100 \mathrm{~g}$, 
respectively. The variation in lignin content might be related to the genetic makeup of different cultivars and growing conditions [18].

The results of this study are consistent with the previous reports for the lignin content of flaxseed of different origin. For Cambridge and Argentinian cultivars of flaxseed SECO content have been reported to be 1262 and $880 \mathrm{mg} / 100 \mathrm{~g}$. Similarly, Swedish origin flax showed the SDG content in the range of 1410 to $2590 \mathrm{mg} / 100 \mathrm{~g}$ in 27 different cultivars of flaxseeds. The phenolic acids present in the different flaxseed cultivars as analyzed by HPLC were gallic acid, caffeic acid, hydroxy benzoic acid, benzoic acid, coumaric acid, ferulic acid and cinnamic acid.
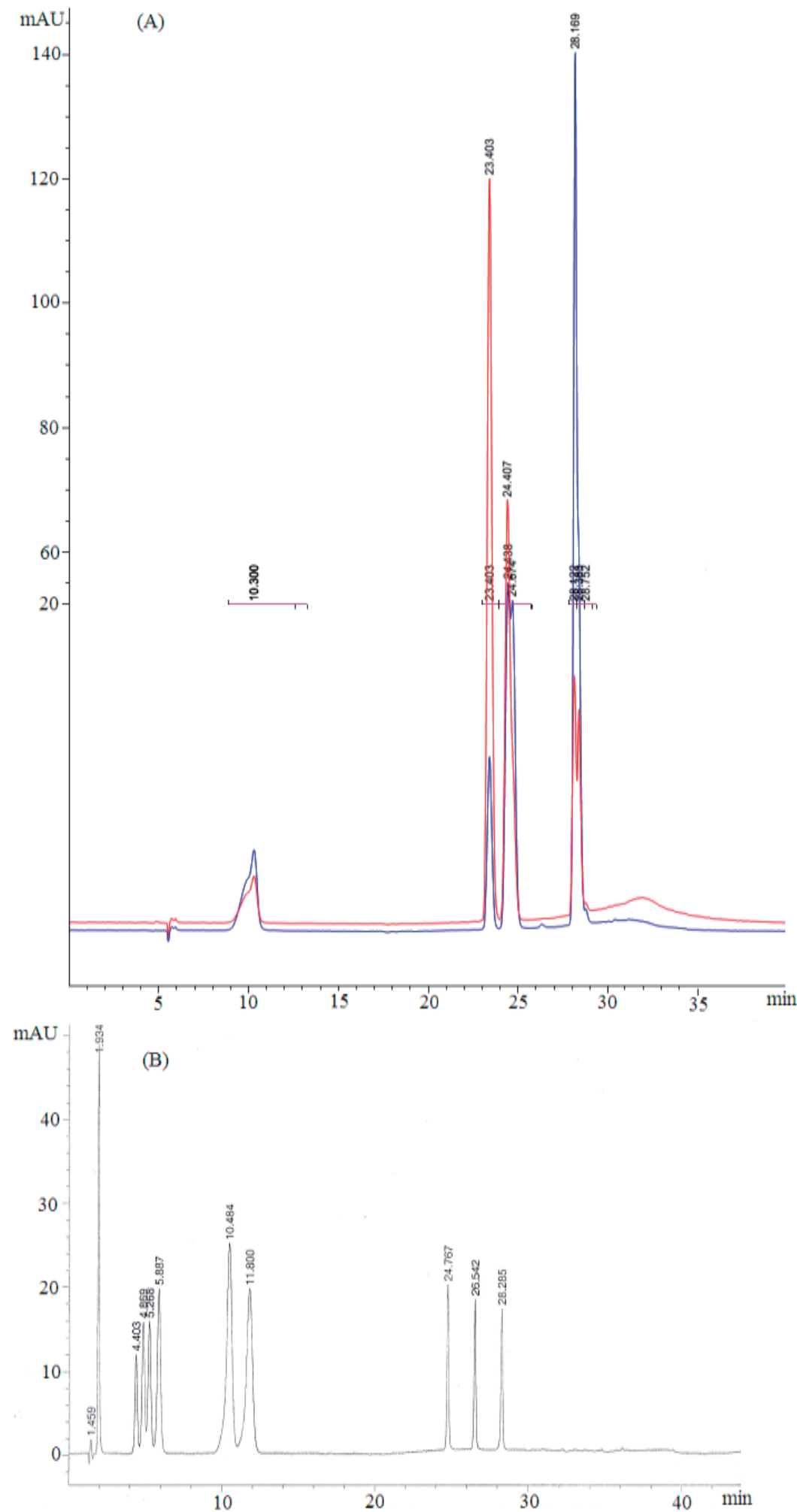

Fig. 1. HPLC chromatograms of the phenolic compounds: (A) standards mixture and (B) ethanolic extract of flaxseed LS-13 cultivar. 
Among the phenolic acid, ferulic and coumaric acid were in abundant as compared to the others and were in the range of 15.22 to 127.2 and 44.76 to $273.83 \mathrm{mg} / 100 \mathrm{~g}$, respectively. The least amount detected was of gallic acid ( 1.47 to $13.16 \mathrm{mg} / 100 \mathrm{~g}$ ) in all the flaxseed cultivars except LS-13 in which it was not detected. Results are consistent with the previous findings in which coumaric and ferulic acid were observed to be present in higher concentrations in flaxseeds cultivars of French origin (370 and $410 \mathrm{mg} / 100 \mathrm{~g}$ ) [23]. In contrast, chlorogenic acid and para-hydroxy benzoic acid were found as major phenolic acid in American flaxseed. Among flavanols, kaempferol was detected in all the cultivars of the flaxseed. The quantity of kaempferol varied significantly in different flaxseed cultivars and was in the range of 2.79 to $28.51 \mathrm{mg} / 100 \mathrm{~g}$. This variation in the qualitative and quantitative composition of phenolic of flaxseed might be due to different varietal genetic makeup and agro-climatic regions of the cultivars. The environment has also an impact on antioxidant activity of extracts.

\section{Conclusions}

Present study was aimed to evaluate the antioxidant activities and phenolic compounds in different cultivars of flaxseed. The results showed that flaxseed had promising antioxidant activities and vary among individual cultivars. The solvent ethanol: water $(80: 20 \mathrm{v} / \mathrm{v})$ was found efficient for the extraction of phenolic compounds from flaxseeds. HPLC analysis revealed the presence of gallic acid, hydroxy benzoic acid, secoisolariciresinol diglucoside, caffeic acid, secoisolariciresinol, coumaric acid, ferulic acid, cinnamic acid, benzoic acid and kaempferol as major components in flaxseed ethanolic extracts. From results, it is concluded that flaxseed had potency as antioxidant for medicinal health functions and functional food and nutraceutical applications. However, there is need to investigate their safety as a natural antioxidant using in vivo bioassays.

\section{Conflict of Interest}

The authors declare no conflict of interest.

\section{References}

1. JHALA A.J., HALL L.M. Flax (Linum usitatissimum L.): Current uses and future applications. Aust J Basic Appl Sci. 4, 4304, 2010.

2. ODELEYE T., LI Y., WHITE W.L., NIE S., CHEN S., WANG J., LU J. The antioxidant potential of the New Zealand surf clams. Food Chem. 204, 141, 2016.

3. ANJUM F., SHAHID M., JILANI M.I., ORANAB S., FAROOQ S., NAZIR A., NAZ S., IQBAL M. Evaluation of Antioxidant Potential and Cytotoxic Behavior of Different
Varieties of Allium sativum. Pol. J. Environ. Stud. 29 (6), 4447, 2020.

4. IQBAL D.N., HUSSAIN E.A., GHANI A., HASSAN F., BUKHARI A., IFTIKHAR S., NAZIR A., AHMAD A., IQBAL M. Green and Environmentally Friendly Techniques for Enhanced Physicochemical Characteristics Attributed to Polysaccharides for Industrial Applications. Pol. J. Environ. Stud. 29 (5), 3457, 2020.

5. JABEEN S., ALI S., NADEEM M., ARIF K., QURESHI N., SHAR G.A., SOOMRO G.A., IQBAL M., NAZIR A., SIDDIQUA U.H. Statistical Modeling for the Extraction of Dye from Natural Source and Industrial Applications. Pol. J. Environ. Stud. 28 (4), 2145, 2019.

6. ARSHAD M., RAHMAN A., QAYYUM A., HUSSAIN K., KHAN M.A., HUSSAIN T., ABBAS M., SHAR G.A., ZAHOOR M.K., NAZIR A., IQBAL M. Environmental Applications and Bio-Profiling of Tribulus Terrestris: an Ecofriendly Approach. Pol. J. Environ. Stud. 29 (4), 2981, 2020.

7. HUSSAIN A., AHMAD M.N., JALAL F., YAMEEN M., FALAK S., NOREEN S., NAZ S., NAZIR A., IFTIKHAR S., SOOMRO G.A., IQBAL M. Investigating the Antibacterial Activity of POMA Nanocomposites. Pol. J. Environ. Stud. 28 (6), 4191, 2019.

8. ALI K., AKHTAR N., SHUAIB M., ALI S., GHAFFAR A., SHAH M., KHAN A., HUSSAIN F., KHAN Z., KALEEM I., NAZIR A., IQBAL M. Impact of Urbanization on Vegetation: a Survey of Peshawar, Pakistan. Pol. J. Environ. Stud. 28 (4), 2523, 2019.

9. FAHIM S., NISAR N., AHMAD Z., ASGHAR Z., SAID A., ATIF S., GHANI N., QURESHI N., SOOMRO G.A., IQBAL M., NAZIR A. Managing Paper and Pulp Industry By-Product Waste Utilizing Sludge as a Bio-Fertilizer. Pol. J. Environ. Stud. 28 (1), 83, 2019.

10. UKPAKA C.P., NEO O.N. Modeling of Azadirachta indica leaves powder efficiency for the remediation of soil contaminated with crude oil. Chem. Int. 7 (1), 62, 2021.

11. SHAMMOUT M.W., AWWAD A.M. A novel route for the synthesis of copper oxide nanoparticles using Bougainvillea plant flowers extract and antifungal activity evaluation. Chem. Int. 7 (1), 71, 2021.

12. SANDA M.D.A., BADU M., AWUDZA J.A.M., BOADI N.O. Development of $\mathrm{TiO}_{2}$-based dye-sensitized solar cells using natural dyes extracted from some plant-based materials. Chem. Int. 7 (1), 9, 2021.

13. AMER M.W., AWWAD A.M. Green synthesis of copper nanoparticles by Citrus limon fruits extract, characterization and antibacterial activity. Chem. Int. 7 (1), $1,2021$.

14. CHAOVANALIKIT A., WROLSTAD R. Total anthocyanins and total phenolics of fresh and processed cherries and their antioxidant properties. J. Food Sci. 69, 67, 2004.

15. IQBAL S., BHANGER M., ANWAR F. Antioxidant properties and components of some commercially available varieties of rice bran in Pakistan, Food Chem. 93, 265, 2005.

16. YEN G.C., DUH P.D., CHUANG D.Y. Antioxidant activity of anthraquinones and anthrone. Food Chem. 70, 437, 2000.

17. TOKUŞOĞLU O., ÜNAL M., YILDIRIM Z. HPLC-UV and GC-MS characterization of the flavonol aglycons quercetin, kaempferol, and myricetin in tomato pastes and other tomato-based products, Acta Chromatogr. 13, 196, 2003. 
18. ANWAR F., PRZYBYLSKI R. Effect of solvents extraction on total phenolics and antioxidant activity of extracts from flaxseed (Linum usitatissimum L.). Acta Sci. Pol. Technol. Aliment. 11, 293, 2012.

19. EL-BELTAGI H., SALAMA Z., EL-HARIRI D. Evaluation of fatty acids profile and the content of some secondary metabolites in seeds of different flax cultivars (Linum usitatissimum L.), Gen. Appl. Plant Physiol. 33, 187, 2007.

20. BARBARY O., EL-SOHAIMY S., EL-SAADANI M., ZEITOUN A. Antioxidant, antimicrobial and anti-HCV activities of lignan extracted from flaxseed. Res. J. Agric. Biol. Sci. 6, 247, 2010.
21. KASOTE D., HEGDE M., DESHMUKH K. Antioxidant activity of phenolic components from n-butanol fraction (PC-BF) of defatted flaxseed meal. Am. J. Food Tech. 6, 604, 2011.

22. IQBAL M., ABBAS M., NISAR J., NAZIR A., QAMAR A. Bioassays based on higher plants as excellent dosimeters for ecotoxicity monitoring: a review. Chem. Int. 5 (1), 1, 2019.

23. BEEJMOHUN V., FLINIAUX O., GRAND E., LAMBLIN F., BENSADDEK L., CHRISTEN P., KOVENSKY J., FLINIAUX M.A., MESNARD F. Microwave-assisted extraction of the main phenolic compounds in flaxseed. Phytochem. Anal. 18, 275, 2007. 